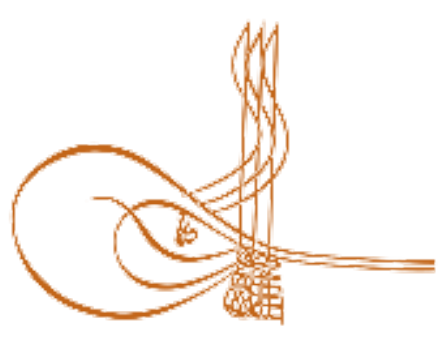

www.turkishstudies.net/education
Turkish Studies - Educational Sciences

eISSN: 2667-5609

Research Article / Araștırma Makalesi

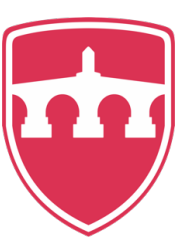

INTERNATIONAL BALKAN

UNIVERSITY

Sponsored by IBU

\title{
Duyuşsal Alan Hedeflerinin Gerçekleşmesinde Dijital Teknolojinin Etkililiğine İlişkin Öğretmen Görüsşleri
}

\author{
Teachers' Opinions on the Effectiveness of Digital Technology in Achieving Affective Domain \\ Objectives $^{1}$
}

\author{
Dinçer Temelli $^{*}$ - Çavuş Şahin ${ }^{* *}$ - Osman Yılmaz Kartal ${ }^{* * *}$
}

\begin{abstract}
The information technologies have a great importance for the people, since they facilitate the life and institutions' acts and processes. The information technologies that are used in education system, are expected to be an effective tool for achieving in educational goals. In the education process, goals are determined according to the learning areas and the goals are tried to be gained in the determined areas. Affective objectives are of particular importance. Limitations in achieving affective goals lie at the root of students' alienation to education. It is thought that digital technologies can have a significant effect on the elimination of the limitations in the achievement of affective objectives and on the achievement of these objectives. For this reason, the opinions of the teachers who are the implementers of the curriculum are important. This research is designed according to the explanatory sequential mixed research design. The principles of research and publication ethics were respected in the research. The data of the research were collected in 2017. "A questionnaire of technology beliefs for affective objectives" and semi-structured interview form developed by the researchers were used for conduct this research. At the end of the research, it was observed that teachers have strong opinions about the effectiveness of technologies in gaining affective objectives. Smart boards and Web 2.0 are thought the most effective tool by the teachers. Respectively, computer, tablet pc, smartphone, web 1.0 come next in that list. Effectiveness of smart board is explained by
\end{abstract}

\footnotetext{
${ }^{1} \mathrm{Bu}$ çalışma birinci yazarın "Öğretmenlerin Bilişsel ve Duyuşsal Hedeflerin Kazandırılmasında Teknolojinin Etkililiğine İlişkin İnançları" başlıklı doktora tezinden üretilmiştir. Araştırmanın verileri 2017 yılında toplanmış, Turkish Studies Educational Science dergisine aday makale olarak 2019 yılında gönderilmiştir.

* Dr., Bilişim Teknolojileri Öğretmeni, 100. Yıl Barış Ortaokulu

Dr., ICT Teacher, 100. Yll Baris Secondary School

ORCID 0000-0001-6258-5049

dincer0182@gmail.com

** Prof. Dr., Çanakkale Onsekiz Mart Üniversitesi, Eğitim Fakültesi, Temel Eğitim Bölümü

Prof. Dr., Canakkale Onsekiz Mart University, Faculty of Education, Department of Primary Education

ORCID 0000-0002-4250-9898

csahin25240@yahoo.com

*** Doç. Dr., Çanakkale Onsekiz Mart Üniversitesi, Eğitim Fakültesi, Eğitim Bilimleri Bölümü

Assoc. Prof. Dr., Canakkale Onsekiz Mart University, Faculty of Education, Department of Educational Sciences

ORCID 0000-0003-2922-0069

oykarta179@yahoo.com
}

Cite as/ Atıf: Temelli, D. \& Şahin, Ç. \& Kartal, O. Y. (2020). Duyuşsal alan hedeflerinin gerçekleşmesinde dijital teknolojinin etkililiğine ilişkin öğretmen görüşleri, Turkish Studies - Education, 15(2), 1233-1249. https://dx.doi.org/10.29228/TurkishStudies.39343

Received/Geliş: 18 October/Ekim 2019

Accepted/Kabul: 23 April/Nisan 2020

Copyright (C) INTAC LTD, Turkey 
"affective experience" and "motivation" parameters; and also the effectiveness of Web 2.0 is explained by the parameters of "social cohesion" and "autonomy".

Structured Abstract: Introduction According to PISA data absentee rate in Turkey it is higher than the OECD countries (Taş, Arıcı, Ozarkan and Özgürlük, 2016). Absenteeism is the basis of alienation from school. Students who are alienated from school are also experiencing feelings of inability to participate in activities, inability to communicate, low academic achievement, apathy and dissatisfaction (Kaya and Tümkaya, 2017). In particular, it is seen that dijital technology has been used in these processes to attract students to learning environment, to make them take an active role in academic life, to improve their academic development and to increase their interest and motivation (Chang, 2002; Chen, Chiang and Lin, 2013; Kausar, Choudhry and Gujjar, 2008; Yang and Teng, 2014). These studies show that there is a potential of educational technologies for minimizing the limitations of achieving affective education goals. In this study, it is aimed to examine the opinions of teachers about the effect of the dijital technologies used in education on the realization of educational objectives and to investigate the academic reasons of these opinions.

\section{Method}

In this study, the explanatory sequential design is the basis of theresearch desing. The population of the study is formed by six branches of teachers working in Çanakkale province. The quantitative sample of the study consisted of 267 participants. The qualitative study group of the research consisted of 22 participants. For quantitative part of the study consisted of 48 items as data, "a questionnaire of technology beliefs for affective objectives"; that is developed by the researchers, has been used. The content validity of the questionnaire was examined by 6 faculty members who are experts in the field of educational sciences and educational evaluation. For the reliability of the measuring instrument, "split-half reliability" technique was performed. For the qualitative part of the study, interviews have been made with two focal group consisted of one participant from each of the six branches. In addition, individual interviews were held with 10 participants from the branches involved in the research. In the qualitative part of the study, a semistructured interview form was developed by the researchers to analyze the quantitative findings in depth. Expert opinion was obtained regarding the validity of the interview form. Pilot interviews were held with teachers.

\section{Result and Discussion}

According to the opinions of teachers about the effectiveness of the technologies used in education in realizing affective field objectives, it is seen that the affective area's opinions about the effectiveness of technology in receiving, responding, valuing, organization and characterization by a value or value complex processes are generally high. Considering the educational technologies examined in the study, the most smart board is the most important in realizing the affective targets and then respectively web 2.0 , computer, tablet pc, smartphone, web 1.0 come next in that list.

In the studies conducted in terms of affective objectives related to the affective field, it was found that web 2.0 tools increased the motivation of the students (Baş, and Tüzün, 2007) and increased the student's attitude towards the course (Katwibun, 2014; Özerbaş, 2012), computer-based education has developed a positive attitude towards the course according to the traditional method (Özabacı and Olgun, 2011; Yenice, 2003) and poses positive changes in students' perceptions (Mevarech and Rich, 1985), web 2.0 applications, as well as motivation, self-confidence has been raised (Kurtuluş, Ada and Burn, 2014) was put forward. Research shows that the use of technology in the educational environment enables students to develop positive attitudes towards the lesson by attracting their attention and motivation, giving importance to the lesson and realizing the affective objectives of the course.

In the interviews, the teachers stated that the visual, auditory and different applications of the smart board increased the student's interest in the lesson and motivated the student to participate in the class. This situation shows that the smart board motivates the students in the process of realizing the affective goals to be given to the students. Similarly, in studies conducted, they stated that the smart board increased the interest and participation of the students in the lesson, and that their motivation improved in a positive way (Katwibun, 2014; Balkaş and Barış, 2015; Yıldızhan, 2013; Erduran and Tataroğlu, 2009; Bush, Priest, and Coe, 2004; Shenton and Pagett, 2007; Troff and Tirotta, 2009; Kaya and Aydın, 2011). There are studies 
showing that the smart board is an effective learning tool to increase students' interest and motivation. The smart board strongly supports students with special learning needs (Chou, Chang and Chen, 2017). It has been stated that the use of EBA from Web 2.0 tools facilitates classroom management as it increases the interest in the course (Çakmak and Taşkıran, 2017).

It has been stated that the students who use Web 2.0 tools are adapting to the structure of the environment and have created an environment in which the students are socialized through communication with each other and with their teachers. This situation states that the participants who communicate with each other on the web 2.0 tools act in accordance with the environment in which they are sharing and provide social cohesion and autonomous behaviors. Similarly, Klimova and Poulova (2015) stated that the students on social network increased communication and that the students developed the class relations through the relationship they established with the teacher; Šliogerienuc, Masoodi and Gulbinskien için (2016) found that facebook could be used to improve the sense of autonomy.

As a result, the smart board allows the student to pay attention to the lesson, the desire to make transactions on the smart board contributes positively to gain the affective objectives of the course by increasing confidence and motivation. Web 2.0 tools, through social interaction and course, provide the environments where students connect with each other, communicate, socialize, express themselves and trust themselves. From this point of view, it is recommended that the integration of technology into education, the examination of the professional competences related to technology, and the creation of guidelines for the use of technology in gaining training objectives for teachers. In this way, it will be easier to achieve the goals set in education.

Keywords: Affective Taxonomy, Educational Objectives, Educational Technologies, Interactive Whiteboard, Web 2.0.

Öz: Bilişim teknolojileri, yaşamın ve toplumsal kurumların iş ve işlemlerini kolaylaştırması bakımından bireyler için önemli bir yere sahiptir. Her alanda olduğu gibi eğitim sisteminde de etkin rol oynayan bilişim teknolojilerinin, eğitim hedeflerinin kazandırılmasında etkili bir araç olarak kullanılması beklenmektedir. Eğitim sürecinde öğrenme alanlarına göre hedefler belirlenmekte ve belirlenen alanlardaki hedeflerin kazandırılmasına çalışılmaktadır. Bu hedefler arasında duyuşsal hedefler ayrı bir öneme sahiptir. Öğrencilerin eğitime yabancılaşmasının temelinde, duyuşsal hedeflerin kazandırılmasındaki sınırlılıklar yer almaktadır. Duyuşsal alan hedeflerin kazandırılmasında yaşanan sınırlılıkların giderilmesi ve duyuşsal hedeflerin kazandırılmasında dijital teknolojilerin önemli bir etkisinin olabileceği düşünülmektedir. Bu nedenle eğitim programlarının uygulayıcısı olan öğretmenlerin bu konudaki değerlendirmeleri önemlidir. Bu araştırmada, duyuşsal hedeflerin kazandırılmasında dijital teknolojinin etkililik düzeyinin öğretmen görüşlerine göre incelenmesi amaçlanmaktadır. Karma yöntem üzerinden gerçekleştirilen araştırmanın tasarımında "açıklayıcı sıralı karma yöntem" temel oluşturmaktadır. Araştırma sürecinde araştırma ve yayın etiği ilkelerine uyulmuştur. Araştırmanın verileri 2017 yılında toplanmıştır. Verilerin toplanmasında, araştırmacılar tarafından geliştirilen "Duyuşsal Hedeflerin Kazanımına Yönelik Teknoloji İnançları Anketi" ve yarı yapılandırılmış görüşme formu uygulanmıştır. Araştırma sonunda öğretmenlerin duyuşsal hedeflerin kazandırılmasında dijital teknolojilerin etkililiğine ilişkin görüşlerinin, genelde, yüksek düzeyde olduğu sonucuna ulaşılmıştır. Öğretmenler tarafından en çok akıllı tahta ve Web 2.0 etkili olarak görülürken, sırasıyla bilgisayar, tablet pc/akıllı telefon ve Web 1.0 yer almaktadır. Akıllı tahtanın etkili olarak görülmesi "duyuşsal tecrübe" ve "motivasyon"; Web 2.0'nin etkili olarak görülmesi ise "sosyal uyum" ve "özerklik" parametreleri ile açıklanmaktadır.

Anahtar Kelimeler: Duyuşsal Taksonomi, Eğitim Hedefleri, Eğitim Teknolojileri, Akıllı Tahta, Web 2.0.

\section{Giriş}

Geçmişten günümüze bütün toplumlarda eğitim, insan yetiştirmek için bir araç olarak kullanılmıştır. İnsanın varoluşuyla birlikte beraberinde getirdiği özelliklerde onun eğitilmesini zorunlu hale getirmiştir (Kıncal, 2011). Durkheim (1956), eğitimi yetişmiş nesillerin toplumsal hayata henüz hazır olmayanlar üzerindeki etkisi olarak tanımlarken; Dewey (2004), eğitimi en geniş anlamıyla toplumsal sürekliliğin sağlanabilmesi için bir araç olarak görmektedir. Yapılan bu 
tanımlar eğitimin toplumsal yapı üzerindeki katkısına vurgu yaparken, Ertürk (1972) eğitimi "bireyin davranışlarında kendi yaşantısı yoluyla kasıtlı olarak istendik değişme meydana getirme süreci" olarak tanımlamıştır. Dolayısıyla, eğitim bireyin toplumsallaşma ve kültürlenme süreci olarak öne çıkmaktadır.

Eğitim bir sistemdir ve her sistemde olduğu gibi eğitimde programlanabilir bir yapıya sahiptir (Akpınar, 2003). Eğitim programları birbiri ile dinamik ilişkilere sahip hedef, içerik, öğrenme-öğretme süreçleri ve değerlendirme öğelerinden oluşmaktadır (Bümen, 2006). Öğrenciye kazandırılmak istenen özellikler olarak tanımlanan hedefler öğretimin yönlendirilmesi süreci, öğretme-öğrenme işlemlerinin yapılması ve ölçme işlemine kılavuzluk yapması açısından önemlidir (Demirel, 2015). Belirlenen hedefler formal eğitim sürecinde kazandırılmaya çalışılmaktadır. Kazandırılacak olan hedeflerin tanımlanması; okulların imkanının ve zamanının sınırlılığı gibi çeşitli değişkenler göz önünde bulundurulduğunda, başarıya ulaşma açısından önemlidir (Bloom, 1956). Bu nedenle eğitim hedefleri belirlenirken kazandırılması planlanan bilgi, beceri ve tutumların hangi seviyede gerçekleşeceğinin belirlenmesi gerekir. Öğrenci özellikleri de dikkate alınarak hedefler belirlenme ve sinıflandırılma durumundadır (Arı, 2013).

\subsection{Duyuşsal Alan}

Hedeflerin sınıflandırılmasında öğrenme alanına yönelik davranışlar bilişsel, duyuşsal ve psikomotor olarak üç alan altında ele alınmaktadır (Krathwohl, Bloom ve Masia, 1973).

Bireyin duygularını içeren duyuşsal davranışlar en geniş anlamıyla bireye kazandırılmak istenen duygular, tercihler, değerler, ahlaki kurallar, istek ve güdüler gibi özelliklerin ön planda olduğu bir alandır (Bacanlı, 2006). Duyuşsal alan içerisinde yer alan davranışların birçoğu diğer alanlara göre doğrudan gözlemlenemeyebilir. Duyuşsal davranışlar her bireyde değişebildiği için duyuşsal davranışın tanımlanması ve ölçülmesinde bazı zorluklar meydana gelmektedir. Aynı zamanda çocuklukta ortaya çıkan duyuşsal davranışların gelişimi de uzun bir süreç almaktadır. Yaşanan bu zorluklar nedeni ile öğrencide bulunması hedeflenen davranışın gelişimi için öğrencinin aile, okul, arkadaş çevresi gibi ortamlarda işlevsel etkileşim içerisinde olması gerekmektedir (Atılgan, 2011).

Duyuşsal alan içinde yer alan davranışlar bireyin sadece okul hayatı içinde değil aynı zamanda okul dışı ortamlarda da oluşturabileceği davranışlardır. Bireyin okul hayatında öğrendiği davranışlar ile toplum yaşamında öğrendiği davranışlar bazen çelişkilerin doğmasına neden olabilmektedir. Bu nedenle işlevsel yönde davranış kazandırmada okul önemli bir yere sahiptir (Sönmez, 2004). Çünkü duyuşsal davranışlar, öğrencilerin öğrenme sürecinde nasıl hissettikleri ve öğrenim sürecini nasıl içselleştirdikleri ile ilgilidir. $\mathrm{Bu}$ durum öğretmenlerin; öğrencilerin gelecekteki tutum, görüş ve davranışlarını yönlendirilebilmesi açısından önemlidir (Miller, 2010).

Duyuşsal alan ile ilgili ortaya konulan davranışlar kendi başına bir hedef davranış olmakla birlikte aynı zamanda bilişsel ve psikomotor alan davranışlarının kazanılmasında kolaylaştırıcı bir yapıya sahiptir (Atılgan, 2011). Bu durum farklı öğrenme alanlarının birbirleriyle olan ilişkisini göstermektedir. (Sönmez, 2004). Etkili bir öğretmen öğrencilerin duyuşsal özelliklerinin öğretmeöğrenme sürecinde oynadığı rolün öneminden hareketle, öğretimi planlamada duyuşsal alanı dikkate alır ve olumlu duyuşsal özelliklerin gelişmesine de rehber olur (Senemoğlu, 2005). Öğretmenler kendi dersleri ile ilgili belirlenen duyuşsal davranışların kazandırılmasına çaba harcamalıdır. Duyuşsal davranışların yerine getirilmesi, okul ortamında bütüncül bir ilerlemeyi de sağlayacaktır.

Duyuşsal alanda yer alan hedeflerin sinıflandırılması 1964 yılında Kratwohl, Bloom ve Masia tarafından yapılmıştır. Bu sınıflandırma yapılırken duyuşsal alanın yapısal zorlukları "içselleştirme" kavramı ile çözülmüş, duyuşsal alan taksonomisi olarak ana ve alt basamaklardan oluşan bir taksonomi oluşturulmuştur. Duyuşsal alan "alma, tepkide bulunma, değer verme, örgütleme, kişilik haline getirme" basamaklarından oluşmaktadır (Bacanlı, 2006). 
Alma basamağı; duyuşsal alanın en alt basamağı olmakla birlikte öğrenenin duyuşsal anlamdaki ilk tepkisini koyduğu düzeydir. Bu aşama farkında olmayı gerektirir (Küçükahmet, 1999). Öğrenci bu basamakta konu, uyaran, durum veya sorunun farkındadır. "Alma" süreci boyunca öğrenci yeni kavramlarla karşılaşır ve bunları anlamaya çalışır (Krathwohl, Bloom ve Masia, 1973). Buna en temel düzeyde öğrenme çıktılarına, öğrencilerin çevrelerinden yeni kavramlar keşfetmeleri ve onlar hakkında bilgi edinmek için bir isteklilik göstermeleri örnek olarak gösterilebilir (Gano-Phillips, 2009). Alma basamağı öğrencinin bir kişinin, olgunun, olayın veya durumun varlığından haberi olup olmadığını, bilincinde olup olmadığını fark ettiği "farkında olma"; uyarıcının reddedilmediği, uyarıcıya karşı olumlu algısı var ise uyarıcıya hoşgörülü ve açık olduğu "almaya isteklilik"; uyarıcının daha açık ve bilinçli bir şekilde algılandığı, farklı uyarıcılar arasından tercih ettiğini seçebildiği "kontrollü veya seçilmiş dikkat" olmak üzere üç alt basamaktan oluşur (Krathwohl, Bloom ve Masia, 1973).

Tepkide bulunma basamağı; bu basamakta birey karşılaşılan olaylar veya uyarıcılar karşısında bilinçli ve istekli bir şekilde tepkide bulunur, sorulara cevap verir, bir işi yaparken de istekle ve zevkle yapar (Yeşilyurt, 2009). Bu basamakta yer alan öğrencinin algılamayla birlikte kontrollü veya seçici olması beklenmektedir. Örneğin öğrencilerin bir öğretmenin dersine katılması, derste verilen ödevlerini yapması ve öğretmene sorularını sorması öğrencinin öğretmene tepkide bulunduğunun göstergesidir (Gano-Phillips, 2009). Uyarıcının fark edilerek tepkide bulunulduğu bu basamak, uyarıcıya karşı ne bir direnme ne de bir istekliliğin olduğu "tepkide uysallık"; uyarıcıya karşı bireyin kendi isteği doğrultusunda, herhangi bir baskı olmaksızın gerekli davranışı sergilediği "tepkide isteklilik" ve uyarıcı karşısında bireyin zevk aldığı ve haz duyduğu davranışları gösterirken, bu davranışları yerine getiremediğinde ise üzüldüğü, sıkıldığı ve pişmanlık duyduğu "tepkide doyum" alt basamaklarından oluşur (Atılgan, 2011; Sönmez, 2004).

Değer verme basamağı; "değer"in sahip olduğu soyut kavram, bireyin kısmen kendi değerlendirmesinin bir sonucudur. Değer verme, yavaş yavaş içselleştirilen veya kabul edilen öğrenci tarafından kullanılmaya başlanan sosyal bir üründür. Bu seviyede sınıflandırılmış olan davranış, değeri açıkça tanımlanabilecek kadar tutarlı ve kararlıdır (Krathwohl, Bloom ve Masia, 1973). Örneğin öğrencilerin laboratuvarda işlenen derslerde, laboratuvar malzemelerini ve donanımını güvenli bir şekilde ele almaları değer verme davranışının oluştuğunu göstermektedir (Gronlund ve Brookhart, 2009'dan akt: Gano-Phillips, 2009). Değer verme basamağında öğrencinin değer verdiği (ders, konu, öğretmen) şeye karşı bir bağlılık davranışı sergilemesi beklenir. Bu basamak değer verilen bir şeye karşı gösterilen ilginin sürekli ve tutarlı olduğu "bir değeri kabullenmişlik"; var olan değer yargılarından birinin diğerine tercih edildiği "bir değeri yeğleyiş" ve edinilen değere bağlanarak onu yaşam biçimi haline getirme, değeri yaşatma ve yayma için çaba harcama süreci olan "bir değere adama" alt basamaklarından oluşur (Atılgan, 2011; Sönmez, 2004).

Örgütleme basamağı; Öğrenen art arda değerleri içselleştirirken aynı zamanda birden fazla değerin uygun olduğu durumlarla da karşılaşır. Dolayısıyla değerlerin organizasyonu, değerlerin aralarındaki ilişkilerin belirlenmesi, baskın ve yaygın olan değerlerin inşası gerekliliği ortaya çıkar. Böyle bir sistem kademeli olarak kurulur, yeni değerler dahil edildiğinde değişebilir (Krathwohl, Bloom ve Masia, 1973).

Şimdiye kadar başkalarının değerlerini benimseyen bireyin, başkalarının veya toplumun değerlerini kendi içinde inceleyerek karşılaştırması, farkları ve benzerlikleri kıyaslaması, değerler arasında fark edilen çatışmaları çözmesi ve değerler sistemini oluşturacak birleştirme işleminin gerçekleşmesi örgütleme basamağında gerçekleşir. Örgütleme davranışında, birey kendisinin yeterli ve yetersiz yanlarını kabul ederek, yeni değerler oluşturmaya başlar (Atılgan, 2011). Mesleki etik standartların kabul edilmesi veya iş ve kişisel değerleri dengeleyen bir yaşam planının formülasyonu gibi öğrenme çıtılları örgütleme düzeyine ait örneklerdir (Gano-Phillips, 2009). Bu basamak kişinin tüm duyuşsal değerleri inceleyerek kendi benimsediği değere yeni bir anlam 
verdiği, eskisinden tümüyle farklı olmayan geliştirilmiş ve zenginleştirilmiş değeri kavramsallaştırdığı "bir değerin kavramsallaştırılması"; kişinin benimsemiş olduğu ya da çevresindeki değerleri araştırma ve inceleme sonucu kendi içinde tutarlı ve uyumlu değerlere ulaştığı bir sentezi gerçekleştirdiği "bir değer sistemi örgütleme" olmak üzere iki alt basamaktan oluşur (Sönmez, 2004).

Kişilik haline getirme basamağı; içselleştirme düzeyinde değerlerin bireyin sahip olduğu değerler hiyerarşisinde bir yeri vardır. Bireyin bu içselleştirdiği değerlere uygun bir şekilde davranması beklenir. Burada bireyin kendine has kişisel özellikleri ve bireyin hayat felsefesi veya dünya görüşü tanımlanmaktadır (Krathwohl, Bloom ve Masia, 1973). Belli değerlerin kontrollü biçimde genellendiği bu basamak duyuşsal alanın en üst seviyesidir (Küçükahmet, 2009). Bireyin tüm hayatı boyunca oluşturmuş olduğu duyuşsal özellikler artık tutarlı, geniş kapsamlı ve zenginleşmiş̧ir (Atılgan, 2011; Sönmez, 2004). Bu düzeydeki öğrenme çıktılarına örnek olarak; sahip olduğu projeye veya verilen göreve bakılmaksızın bağımsız olarak çalışırken kendine güvenen bir öğrencinin, problemleri bağımsız olarak çözme becerisine ilişkin tutarlı bir sonuca varması gösterilebilir. Bir diğer örnek ise öğrencinin örgütleme basamağında kabul ettiği mesleki etik standartlarını bu basamakta, etik uygulamalara günlük bir bağlılık davranışına dönüştürmesi olabilir (Gano-Phillips, 2009). Bu basamak, bireyin herhangi bir durum karşısında benzer tepkisi ile nitelendirilen "genellenmiş örüntü"; bireyin sahip olduğu inançların, fikirlerin ve tutumların hayat felsefesi veya dünya görüşüne entegrasyonunu içeren "niteleme" olmak üzere iki alt basamaktan oluşur (Krathwohl, Bloom ve Masia, 1973).

\subsection{Eğitim Teknolojileri}

Günümüzde neredeyse her alanda etkili olan teknoloji; ürünler geliştirmek, üretmek ve kullanmak için yapılan, insanlar ve dünya üzerinde etkileri olan çalışmalar olarak ifade edilmektedir (Wright, Israel ve Lauda, 1993). İnsanoğlunun bilgisine bağlı olarak sürekli gelişen teknoloji ve teknolojik gelişmeler sonrası ortaya çıkan araç ve gereçler, insanlar ve toplumların araştırma ve üretme yapmasına olumlu katkı sağlamıştır (Taş ve Düz, 2016). Bununla birlikte gelişen teknolojiler, insanları ve toplumsal kurumları etkileyerek gelişimlerini ve değişimlerini sağlayan önemli bir unsur olmuştur. Eğitim alanı da teknolojide yaşanan gelişmelerden etkilenmiş ve yeni gelişmeler ışığında kendisini zaman içerisinde yenilemeye çalışmıştır.

Teknoloji, eğitim aracılığı ile elde edilen bilgilerin ve becerilerin verimli bir şekilde kullanılmasına ve uygulanmasına yardımcı olmaktadır (Alkan, 2011). Eğitimde kullanılan teknolojiler; genel hedefleri gerçekleştirmek, öğretim ve öğrenme ile ilgili problemleri çözmek ve desteklemek için kullanılabilecek teknolojik süreçlerin ve en güncel araçların uygulanması olarak görülmektedir (Lever-Dufy ve Mcdonald, 2008; Newby, Stepich, Lehman ve Russell, 2006; Roblyer, 2006; Seels ve Richey 1994). Geçmişten günümüze eğitimde birçok teknoloji kullanıldı ve kullanılmaya devam edilmektedir. Bilgisayar, akıllı tahta, tablet, ak1llı telefon, web 1.0 ve web 2.0 teknolojileri bunlardan bazılarıdır. Bu teknolojiler eğitim hedeflerinin gerçekleştirilmesi sürecinde kullanılan bir araç olarak önemli bir rol almıştır.

Eğitim ortamının ilk teknolojik (dijital) araçları arasında olan bilgisayarlar uzun bir süredir eğitimde kullanılmaktadır. Gelişen teknolojiler sayesinde ortaya çıkan akıllı tahta, mobil cihazlar ve web 2.0 uygulamaları gibi yeni teknolojiler de artık sınıf ortamında eğitim sürecinde daha yoğun bir şekilde kullanılmaya başlanmıştır.

Akıllı tahtalar, dokunmatik ekranın sağladığı iletişim ile birlikte sesler, görseller, video veya animasyonlar üzerinde istenilen işlemlerin yapılması özellikleri ile derslere daha fazla etkileşim, görsellik ve canlılık kazandıran bir teknolojidir (Erduran ve Tataroğlu, 2009). Akıllı tahtalar öğretmenlerin derslerini verimli bir şekilde işlemesine, çeşitliliğe ve esnekliğe imkan sağlarken, sınırsız kaynak ulaşımı ve uygulamalara erişim fırsatları ile etkili eğitim ortamları sağlamaktadır (Slay, Siebörger ve Hodgkinson-Williams, 2008). 
Akıllı tahtalar gibi gelişen teknolojilerin bir ürünü ve günlük yaşamın neredeyse vazgeçilmezi haline gelen diğer bir teknoloji ise Web 2.0 uygulamalarıdır. İnternet teknolojisi ile ortaya çıkan Web 1.0'ın tek yönlü, iletişimsiz ve durağan yapısı geliştirilerek sürekli güncellenen, dinamik, insanlar arası etkileşimli bir yapı olan Web 2.0 oluşturulmuştur. Web 2.0 uygulamaları ile kullanıcıların bilgilerini paylaşabilmesi, kullanıcıların ortak fikirde bir araya gelebilmesi, işbirliği içinde fikir alışverişinde bulunabilmesi sağlanmaktadır (Çemrek, Baykuş ve Özaydın, 2014). Web 2.0 uygulamaları; bloglar, wikiler, ortak belgeler de dahil olmak üzere, öğrenme etkinliklerinde kavram eşleme, VoiceThread, video paylaşım uygulamaları (ör. YouTube), mikroblogging (ör. Twitter), sosyal paylaşım siteleri ve sosyal yer imi içerir (Hsu, Ching ve Grabowski, 2014). Bu uygulamalara gelişen internet teknolojisi ve mobil cihazlarla (akıllı telefon, tablet vb.) ulaşımın artık daha kolay ve hızlı olması 2020'li yılların vazgeçilmezleri arasında olmasını sağlamıştır.

Yeni teknolojilerin yapısal ve işlevsel özellikleri sayesinde ortaya çıkan olumlu özelliklerinin kullanılması, eğitim hedeflerinin gerçekleşmesi sürecinde önemli katkılar sağlayacağı düşünülmektedir.

\subsection{Problem Durumu}

Öğrenenlerin formal eğitimle desteklenmeye çalışılan bilişsel, kişilik, ahlaki, mizah vb. gelişim düzeyleri çeşitli değişkenlerden etkilenmektedir. Bu gelişim düzeylerini hem etkileyen hem de etkilenen bir boyutu duyuşsal alandır ve duyuşsal alanın öğrenen başarısı için önemli bir yeri vardır. Türkiye'nin eğitim göstergeleri incelendiğinde duyuşsal alan kazanımlarının gerçekleşmesi ile ilgili bazı sınırlılıkların olduğu görülmektedir. Örneğin; Uluslararası düzeyde öğrencilerin topluma katılımı için olması gerekli temel bilgi ve becerileri kazanma düzeylerinin değerlendirildiği Uluslararası Öğrenci Değerlendirme Programı - PISA (OECD, 2016) sonuçlarında dikkati çeken veriler arasında, okula yabancılaşma yer almaktadır. Yabancılaşmanın göstergelerinden biri olan devamsızlık oranları incelendiğinde Türkiye açısından olumsuz olarak nitelendirilebilecek bir sonuç ile karşılaşılmaktadır.

PISA 2012 sonuçları uygulamanın yapıldı̆̆ tarih itibariyle son iki haftada en az 3 defa derse girmeyen öğrencilerin oranı OECD ülkelerinde \%3,9 iken Türkiye'de bu oran \%14,7; okula gelmediğini söyleyen öğrenci oranı OECD ülkelerinde \%3 iken Türkiye'de bu oran \%20,5'dir. PISA 2015 uygulamasında ise derse girmeyen öğrencilerin oranı OECD ülkelerinde \%6,6 iken Türkiye'de bu oran \%15; okula gelmediğini söyleyen öğrenci oranı OECD ülkelerinde $\% 5$ iken Türkiye'de bu oran \%17,2'dir (Taş, Arıc1, Ozarkan ve Özgürlük, 2016). 2015 PISA sinavı öncesinde OECD ülkeleri arasında yapılan çalışmada; Türkiye iki haftada bir gün veya daha fazla devamsızlık yapan öğrenci oran $\% 54,2$ ile ilk sırada yer alırken, \%1,5 ile Japonya ise son sırada yer almıştır (OECD, 2014). 2012 ve 2015 verileri, Türkiye'de öğrencilerin ders bazında ve genel olarak okula devamsızlık oranlarının OECD ülkelerinin çok üzerinde olduğunu göstermektedir.

Türkiye'de öğrencinin devamsızlıkları ile ilgili yapılan bazı çalışmalarda öğrencinin başarı anlamında yeterli olmadığ derslerde bulunmak istememesi, derslerin sıkıcı geçmesi, dersi ve okulu sevmeme (Altınkurt, 2008; Gökyer, 2012; Pehlivan, 2006) gibi nedenler yer almaktadır. Okula ve derslere karşı bu şekilde olumsuz duygulara sahip olan öğrenci okula yabancılaşmakta, yabancılaşan öğrenci de akademik anlamda düşük bir başarı gösterme, eğitim ortamındaki etkinliklerde yer almama, iletişime kapalı olma, ilgisizlik ve memnuniyetsizlik gibi duygular yaşamaktadır (Kaya ve Tümkaya, 2017). Bu nedenle eğitim süreci açısından okula yabancılaşmayı en aza indirgeyebilmek için derslerde gösterilen öğrenme alanına ilişkin ilgi, sevgi, değer verme, farkındalık vb. davranışların oluşturulmasının, dersin duyuşsal hedeflerinin oluşturulmasının ve kazandırılmaya çalışılmasının duyuşsal anlamda yaşanan bu sınırlılıkları en aza indirgemesini sağlaması beklenmektedir.

Özellikle, 2000 yılından sonra dijital teknolojinin gelişimi ile birlikte, öğrencileri öğrenme ortamına çekerek etkin rol almasını sağlamak, akademik olarak gelişimini sağlamak, derse karşı 
ilgi ve motivasyonlarını arttırmak için teknolojinin aktif olarak kullanıldı̆̆ görülmektedir (Chang, 2002; Chen, Chiang ve Lin, 2013; Kausar, Choudhry ve Gujjar, 2008; Ramma, Bholoa, Watts ve Nadal, 2017; Yang ve Teng, 2014). Günlük hayatında teknoloji ile yoğun bir etkileşim içinde olan öğrencileri, kullanılacak eğitim teknolojilerinin sayesinde öğrenme ortamına çekerek, hem bilişsel hem de duyuşsal olarak dersin hedeflerinin kazandırılmasının sağlanması beklenmektedir. Duyuşsal eğitim hedeflerine ulaşmada yaşanan sınırlılıkları en aza indirgemek için eğitim amaçlı kullanan teknolojilerin bir potansiyeli olduğu düşünülmektedir. Bu çalışmada öğretmenlerin eğitimde kullandıkları/kullanabilecekleri dijital teknolojilerin, eğitim hedeflerinin gerçekleşmesindeki etkisine yönelik görüşlerinin incelenmesi ve bu görüşlerin akademik gerekçelerinin araştırılması amaçlanmaktadır. Bu temel amaç çerçevesinde aşağıdaki sorulara cevap aranmıştır:

1. Öğretmenlerin görüşlerine göre, duyuşsal hedeflerin (alma, tepkide bulunma, değer biçme, örgütleme, kişilik haline getirme) kazandırılmasında etkililiği açısından öne çıkan dijital teknolojiler (bilgisayar, akıllı tahta, tablet pc/akıllı telefon, web 1.0, web 2.0) hangileridir?

2. Öğretmenlerin görüşlerine göre duyuşsal hedeflerin gerçekleşmesinde öne çıkan dijital teknolojilerin etkililik nedenleri nelerdir?

\section{Yöntem}

Araştırma problemi karma yöntem ile çözümlenmektedir. Karma yöntem, nicel ve nitel araştırmaların olası sınırlılıklarını azaltarak her iki yaklaşımın birleşimi ya da bütünleştirilmesi ile güçlü bir yapıya sahip olan bir desendir. $\mathrm{Bu}$ araştırmada nicel çalışmanın sonucunda hareketle ortaya çıkan bulguların nitel çalışma ile ayrıntılı bir şekilde cevap arandığı "açıklayıcı sıralı karma yöntemler (The Explanatory Sequential Design)” modeli uygulanmıştır (Creswell, 2017).

Araştırmanın nicel bölümde var olan durumun kendi koşulları içerisinde tanımlandığ betimsel tarama modeli (Karasar, 2006); nitel bölümünde ise nasıl ve niçin soruları temelinde bir olayın derinlemesine incelendiği durum çalışmalarından (Yıldırım ve Şimşek 2016) karmaşık olan durumların nedensel bağlarını açıklayan "açıklayıcı durum çalışması (explanatory case study)" (Yin, 2009) kullanılmıştır. Araştırmanın birinci alt amacı nicel yöntem ile çözümlenmekte ve araştırma kapsamında ele alınan dijital teknoloji araçlarından bilgisayar, akıllı tahta, tablet pc/akıllı telefon, Web 1.0, Web 2.0'nin duyuşsal hedefleri kazandırmadaki etkililik düzeyleri öğretmen görüşlerine göre incelenmektedir. Araştırmanın ikinci alt amacı nitel yöntem ile çözümlenmekte ve birinci alt amaca yönelik ulaşılan sonuçta öne çıkan dijital teknolojilerin etkili olma nedenleri incelenmektedir. Bu kapsamda, ikinci alt amacin incelenmesi, duyuşsal taksonomide etkililiği en yüksek olan akıllı tahta ve web 2.0 teknolojileri üzerinden gerçekleştirilmiştir. Etkililik kaynağının çözümlenmesi sadece bu iki teknoloji için geçerlidir.

Çalışmada nicel desenlemede evren ve örneklem, nitel desenlemede ise çalışma grubu bilgileri aşağıda ayrı ayrı sunulmuştur.

\subsection{Evren ve Örneklem}

Nicel araştırma evrenini Çanakkale ilinde yer alan ortaokullarda görev yapan Türkçe, İngilizce, Din Kültürü ve Ahlak Bilgisi, Matematik, Fen Bilimleri ve Sosyal Bilgiler öğretmenleri oluşturmaktadır. Araştırmanın örneklemi oranlı örneklem (\%5 hata payı) ile belirlenmiş ve $\% 88$ anket geri dönüş oranı ile 267 kişiden oluşmuştur. Anket geri dönüş oranın \%70-80'in üzerinde olması sağlıklı yorum yapılmasını sağlamaktadır (Büyüköztürk vd., 2012).

Örneklemde, İlköğretim Matematik branşında 53 (\%19,9), Fen Bilimleri branşında 50 $(\% 18,7)$, Sosyal Bilgiler branşında 39 (\%14,6), İngilizce branşında $45(\% 16,9)$, Türkçe branşında $54(\% 20,2)$ ve Din Kültürü ve Ahlak Bilgisi branşında 26 (\%9,7) öğretmen çalışmaya katılmıştır. 


\section{2. Çalışma Grubu}

Araştırmanın nitel boyutunda amaçlı örnekleme tekniklerinden maksimum çeşitlilik örneklemesine göre odak ve bireysel görüşme grupları oluşturulmuştur. Maksimum çeşitlilik örneklemede genelleme kaygısı olmamakla birlikte araştırma amacıyla tutarlı olarak belirlenen farklı durumlar arasındaki ortak ya da ayrılan yönler, örüntüler ortaya çıkarmak ve daha geniş bir çerçeveden problemi betimlemek amaçlanmıştır (Büyüköztürk vd., 2012).

Araştırmanın nicel incelemesinde yer alan branşların her birinden birer öğretmen katılmış ve toplamda iki odak grup çalıșması yapılmıștır. Bireysel görüșmelerde de araștırmaya katılan branşların her birinden en az birer kişi olmak kaydı ile toplamda 10 kişi seçilmiştir. Genel itibari ile odak grup görüşmelerine 12 ve bireysel görüşmelere 10 kişi olmak üzere toplamda 22 kişi görüşmelere katılmıştır. Odak grup görüşmelerinde 6-8 (Yıldırım ve Şimşek 2016), 4-8 (Büyüköztürk vd., 2012) ve 6-10 (Ersin ve Bayyurt, 2015) kişiden oluşması gerektiğine dair farklı düşünceler bulunmaktadır. Bu çalışmada 6 kişiden oluşturulan odak grupları, grup büyüklüğü açısından işlevseldir.

\subsection{Veri Toplama Aracı}

Çalışmanın nicel bölümünün veri toplama aracı olarak 10 maddeden oluşan ve araştırmacılar tarafından geliştirilen "Duyuşsal Hedeflerin Kazanımına Yönelik Teknoloji İnançları Anketi” kullanılmıştır. Anketin kapsam geçerliliği Eğitim Bilimleri ve Eğitimde Ölçme Değerlendirme alanlarında uzman olan 6 öğretim elemanı ile gerçekleștirilmiștir. Ölçme aracının güvenirliği için "iki yarı test güvenirliği" tekniği gerçekleştirilmiştir. Anketin test puanları arasındaki tutarlılığın yüksek olduğu, bu da anketin güvenilir olduğunu göstermiştir (en düşük madde $\mathrm{r}=.650$ ve en yüksek $\mathrm{r}=.808$ ). Ankette eğitim ortamında yoğun olarak kullanılan teknolojik araçların duyuşsal hedeflerin gerçekleşmesinde "etkili olacağına hiç inanmıyorum"dan etkili olacağına "tamamen inanıyorum" şeklinde değişen 5'li derecelendirme kullanılmıştır. Farklı branşlardaki öğretmenler, kendi derslerine ilişkin duyuşsal hedefleri dikkate alarak görüşlerini belirtmişlerdir.

Çalışmanın nitel bölümünde ise araştırmacı tarafından nicel bulguların derinlemesine incelenmesi için bir yarı yapılandırılmış görüşme formu hazırlanmıştır. Görüşme formunun geçerliğine ilişkin uzman görüşü alınmıştır. Görüşme formunda bulunan soruların anlaşılabilirliğine bakmak için öğretmenler ile pilot görüşmeler gerçekleştirilmiştir.

\subsection{Verilerin Analizi}

Araştırmanın verilerinin parametrik test koşulları incelenmiştir. Verilerin normal dağılım gösterip göstermediğini incelemede skewness-kurtosis değerleri ile histogram eğrileri dikkate alınmıştır. Skewness ve kurtosis değerlerinin -2 ile +2 değerleri aralığında olması verilerin normal dağıldığının göstergesidir (Lomax ve Hahs-Vaughn, 2012). Verilerin ifade edilen aralık değerlerinde olduğu sonucuna ulaşılmıştır. Betimsel analiz için aritmetik ortalama ve standart sapma sonuçları SPSS 21.0 programı ile yapılmıştır. Verilerin puanlamasında hedeflerin kazandırılmasında teknolojinin etkisine ilişkin görüşleri 1.00-1.50 arası "çok düşük", 1.51-2.50 aras1 "düşük", 2.51-3.50 arası "orta", 3.51-4.50 arası "yüksek" ve 4.51-5.00 arası "çok yüksek" düzey olarak yorumlanmaktadır.

Öğretmen görüşlerinin analizi sürecinde ise yarı-yapılandırılmış odak grup görüşmeleri ve bireysel görüşmeler yapılmış, veriler ses kayıt cihazı ile alınarak MS Word kelime işlemciye birebir aktarılmıştır. Verilerin kodlanması sürecinde nitel veri analizlerinden "içerik analizi" yaklaşımından faydalanılmıştır. İçerik analizinde yapılan kodlama işleminin güvenirlik hesaplaması Miles ve Huberman'ın (1994) sunduğu formül ile gerçekleştirilmiştir; "Güvenirlik = Görüş Birliği / (Görüş Birliği + Görüş Ayrılığı) x 100”. Uygulanan hesaplama işlemi sonunda 
kodlamaların güvenirliği \% 87 bulunmuştur. "Güvenirlik hesaplarının yüzde 70'in üzerinde çıkması, araştırma için güvenilir kabul edilmektedir" (Miles ve Huberman, 1994).

\section{Bulgular}

Araştırmanın alt amaçlarına yönelik gerçekleştirilen analiz sonuçları bu bölümde sunulmaktadır. Önce hedeflerin kazandırılmasında teknolojinin etkililiğine olan görüşlerinin incelenmesi; daha sonra da bu görüşlerin akademik dayanaklarına ilişkin elde edilen bulgu ve yorumların sunumu gerçekleştirilmektedir.

\section{1. Öğretmenlerin Duyuşsal Hedeflerin (Alma, Tepkide Bulunma, Değer Biçme, Örgütleme, Kişilik Haline Getirme) Kazandırılmasında Dijital Teknolojinin Etkili Olma Düzeyine Yönelik Görüşlerinin İncelenmesi}

Duyuşsal taksonominin gerçekleşmesinde dijital eğitim teknolojilerinin etkisine ilişkin öğretmenlerin görüşleri Tablo 1'de sunulmuştur.

Tablo 1. Duyuşsal Alan Basamaklarına Ait Aritmetik Ortalamalar ve Standart Sapmalar

\begin{tabular}{|c|c|c|c|c|c|c|c|c|c|c|}
\hline \multirow{2}{*}{$\begin{array}{l}\text { Kullanılan } \\
\text { Teknolojiler }\end{array}$} & \multicolumn{2}{|c|}{ Alma } & \multicolumn{2}{|c|}{$\begin{array}{c}\text { Tepkide } \\
\text { Bulunma }\end{array}$} & \multicolumn{2}{|c|}{ Değer Verme } & \multicolumn{2}{|c|}{ Örgütleme } & \multicolumn{2}{|c|}{$\begin{array}{l}\text { Kişilik Haline } \\
\text { Getirme }\end{array}$} \\
\hline & $X$ & SS & $\mathrm{X}$ & SS & $\mathrm{X}$ & SS & $\mathrm{X}$ & SS & $\mathrm{X}$ & SS \\
\hline Bilgisayar & 3,89 & 1,02 & 3,70 & 1,00 & 3,76 & 0,99 & 3,57 & 1,06 & 3,56 & 1,00 \\
\hline Ak1llı Tahta & 4,43 & 0,79 & 4,16 & 0,88 & 4,18 & 0,87 & 3,99 & 0,92 & 3,98 & 0,93 \\
\hline Tablet/A.Tel & 3,35 & 1,14 & 3,28 & 1,09 & 3,29 & 1,06 & 3,13 & 0,99 & 3,14 & 1,04 \\
\hline Web 1.0 & 3,21 & 1,06 & 3,05 & 1,02 & 3,07 & 0,99 & 2,96 & 0,97 & 2,93 & 0,99 \\
\hline Web 2.0 & 4,06 & 0,96 & 3,95 & 0,95 & 3,99 & 0,88 & 3,82 & 0,94 & 3,82 & 0,95 \\
\hline
\end{tabular}

Duyuşsal hedeflerin gerçekleşmesinde dijital teknolojinin etkisine yönelik aritmetik ortalamalara bakıldığında; duyuşsal alanın tüm basamaklarında akıllı tahta ilk sırada yer alırken, akı1lı tahtayı sırası ile Web 2.0, bilgisayar, tablet/akıllı telefon ve Web 1.0'1n izlediği görülmektedir.

Duyuşsal alan basamaklarına ilişkin aritmetik ortalamalara bakıldığında öğretmenlerin çalışmada incelenen dijital teknolojilerin duyuşsal hedeflerin kazandırılmasında etkililiğine ilişkin görüşlerinin genel anlamda yüksek olduğu görülmektedir. Bu durum öğretmenlerin duyuşsal alan basamaklarında yer alan hedeflerin kazandırılmasında teknolojiyi etkili bir araç olarak gördüklerini göstermektedir.

\subsection{Duyuşsal Eğitim Hedeflerinin Gerçekleşmesinde Öne Çıkan Dijital Teknolojilerin Etkili Olma Düzeyine İlişskin Öğretmen Görüşlerinin İncelenmesi}

Çalışmada öğretmenlerin görüşlerine göre, duyuşsal hedeflerin kazandırılmasında etkililiği açısından akıllı tahta ve Web 2.0 teknolojilerinin öne çıktığı Tablo 1'de görülmektedir. Araştırmanın birinci alt amacının çözümlenmesinden sonra, ikinci alt amaca temel teşkil eden ve inceleme konusu olan "durum", akıllı tahta ve Web 2.0'nin duyuşsal hedeflerin gerçekleştirilmesindeki etkililiğine ilişkin nedenlerdir. Gerçekleştirilen görüşme ve odak grup görüşmeleri sonucunda ulaşılan sonuçlar Tablo 2'de gösterilmiştir. 
Tablo 2. Akıllı Tahta ve Web 2.0 Araçlarının Duyuşsal Alandaki Hedeflerin Gerçekleşmesindeki Etkililiği Açıklayan Görüşme Sonuçları

\begin{tabular}{lccc}
\multicolumn{1}{c}{$\begin{array}{c}\text { Kategoriler } \\
\text { (Eksensel Kodlama) }\end{array}$} & $\begin{array}{c}\text { Kavramlar } \\
\text { (Seçici Kodlama) }\end{array}$ & $\begin{array}{c}\text { Temalar } \\
\text { (Teorik Kodlama) }\end{array}$ & Kullanılan Araç \\
\hline $\begin{array}{l}\text { İlgi, merak, adapte olma, } \\
\text { dikkat, güdü }\end{array}$ & $\begin{array}{c}\text { Sempati } \\
\text { Duyuşsal Yetkinlik }\end{array}$ & Duyuşsal Tecrübe & AT \\
\hline $\begin{array}{l}\text { Katılım, yapma hissi, haz, } \\
\text { başarma hissi, deneyimleme, } \\
\text { güven, cesaret, }\end{array}$ & Özgüven & Motivasyon & AT \\
\hline $\begin{array}{l}\text { Öğrenci arası bağ kurma, } \\
\text { iletişim, olumlu tepki }\end{array}$ & Sosyalleşme & Sosyal uyum & Web 2.0 \\
\hline $\begin{array}{l}\text { Sorumluluk, güven, } \\
\text { kendini ifade etme, }\end{array}$ & Otonom davranışlar & Özerklik & Web 2.0 \\
\hline
\end{tabular}

- Akı1lı tahta öğrencilerin derse olan motivasyonunu arttırmaktadır. Akıllı tahta öğrencinin derse aktif katılımını sağlayan uygulamalar aracılığı ile derse katılan öğrencinin uygulama başında başarma hissini deneyimleme imkanı vererek özgüveni geliştirir. $\mathrm{Bu}$ konuda öğretmenler görüşlerini şu şekilde belirtmişlerdir;

Ö12 kodlu öğretmen görüşü şu şekildedir "Akıllı tahta en azından görsel ve işitsel olarak hitap ettiği için alglyı kuvvetlendiriyor. Çocuklar tahtadaki simülasyonlara hemen dikkat kesiliyorlar. Akallı tahta uygulamalarının çocuklar için büyük bir haz ve başarma duygusunu tetiklediğini düşünüyorum.”

Ö15 kodlu öğretmen görüşü şu şekildedir: "Akıllı tahta ile ögrenciler aralarında bir băg kuruyor. Tahtaya dokunma onların çok hoşuna gidiyor. Yaparak yaşayarak öğrenmeyi tadiyor aslında. Simülasyon açıyorum, öğrenciler deneyi kendisi yönlendiriyor. Bu da içselleştirme sürecini hızlandırıyor. Kazanımların büyük oranda gerçekleşmesinde etkili oluyor. Öğrenciler bu deneyimleri unutmuyor ve kendine bu deneyimlerden cesaretler yeni deneyimlere yönelebiliyor."

- Web 2.0 araçları öğrencilerin birbirleri ile iletişim halinde olmasını sağlayan bir bağ kurmakta, çekingen öğrencinin rahat olmasını sağlamakta ve öğrencilerin sosyalleşmesini sağlamaktadır. Özellikle sosyal medya ortamlarında ise öğrenciler daha motive olmakta, kendilerini özgürce ifade edebilmekte, kendine güvenmekte ve sosyal ortamların getirdiği sorumlukların farkına varabilmektedir. Bu konuda öğretmenler görüşlerini şu şekilde belirtmişlerdir;

Ö9 kodlu öğretmen görüşü şu şekildedir: "Üretkenlik sosyal medya ortamlarında artmaktadır. Yüz yüze cevap vermeyen ögrenciler sosyal medya ortamlarında ya da Web 2.0 araçların kullanarak fikir alışverişinde bulunarak, derste ögrenemediklerini akran gruplarından ögrenerek başarılarını arttırabilen öğrenciler bulunmaktadır."

Ö4 kodlu öğretmen görüşü şu şekildedir: "Günümüzde sosyal medya ya da ders içerikli bilişim ăgları, forumlar vb. doğru yönlendirmelerle kullanıldı̆̆ında derse yönelik ögrrencilerin duyuşsal yönden gelişmesini sağlayabilir. Bir ögrencinizin paylaşımını beğenmeniz bile o öğrenci için önemli anlamlar taşımasını sağlar. Öğrencilere test verdiğimde yapamayınca sıkılıp bırakıyorlar ama Whatsapp gruplarımda anında geri dönüt verdiğim için, bu böyle yapıllyormuş deyip motive olup çözmeye devam ediyorlar. Öğretmenin grupta öğrencilerin sorularını, paylaşımlarını takip ettiğini bildiği için öğrencinin öğretmene dolayısıyla derse karşı sorumluluğu ve duyarlıliğı artıyor." 
Ö10 kodlu öğretmen görüşü şu şekildedir: “Web 2.0 daha interaktif ve çocuğun her gün kullandiğı teknolojinin olarak yer almaktadır. Artık ögrencileri yorum yapmak, paylaşmak beğeni almak gibi dönütlü yapılar daha çok etkiliyor. Eğitimin özellikle sosyal medyada uygulanması, ögrencinin derse karşı olan isteğini ve güdülenmesini arttırmaktadır."

Ö4 kodlu öğretmen görüşü şu şekildedir: “Web 2.0'da oluşturulan sosyal medya gruplarında bazı ögrencilerin kendini yüzyüze eğitim ortamından daha iyi ifade edebildiğini gördüm. Çekingenliğini sosyal ortamlarda rahatça atmaktadır. Oluşturduğumuz sosyal medya ortamlarında sinıf içinde yeterince söz hakkı almayan veya çekinen ögrencilerin sınıf ortamından daha fazla soru sorduklarına, cevap verdiklerini gördüm. Aynı durum Eğitim Bilişim A $\breve{g}$ (EBA) 'nda da söz konusu, bu ögrenciler sinıf duvarına daha fazla ileti yazabiliyor. Bu da kendini ifade etmekte sıkılan ögrencilerin ögrenmesi, dersi sahiplenmesi için kullanılabilir"

Ö2 kodlu öğretmen görüşü şu şekildedir: "Web 2.0 araçları ile yazışırken kimse onu görmüyor diye tahtaya kalkmaya korkan ögrenci rahatllkla yazlyor. Ingilizce dersinde özellikle yabancı dilde kendini ifade etmek zor oluyor. Web 2.0 araçlar sayesinde özgüven eksikliği gideriliyor ve ögrenci kendine güvenmeye başllyor. Bunun ögretmen tarafindan fark edilmesi ve bu yönde teşvik edilmesi önemlidir."

Ö11 kodlu öğretmen görüşü şu şekildedir: "Sosyal medya çocukların vazgeçilmezi bunu etkin olarak kullanabilirsek, etkinliklerle süsleyebilirsek belki de çocuklarda duyuşsal açıdan derse daha çok ilgi göstermesini ve istediğimiz kazanımların verilmesini sağlayabiliriz”.

$\mathrm{Bu}$ alt amaç doğrultusunda öğretmenlerin duyuşsal hedeflerin kazandırılmasında akıllı tahta ve Web 2.0 araçlarının farklı parametreler 1şı̆̆ında etkisini ortaya koydukları görülmektedir. Yapılan görüşmelerde geleneksel öğretim yerine kullanılan akıllı tahta ve Web 2.0 teknolojileri ile destekli eğitimin; öğrencilerin derse olan ilgisini ve dikkatini arttırdığı, derse karşı istek duymasını sağladığ 1 ve eğitim teknolojilerini deneyimleme imkanı ile öğrencinin derse daha duyarlı ve olumlu tutumlar oluşturduğu ortaya çıkmıştır. Bu durum eğitimde kullanılan bu teknolojilerin öğrencinin dersle bütünleşmesine ve hedeflerin kazandırılmasına yardımcı olduğunu göstermektedir. Özellikle web 2.0 araçlarının yeni bir eğitim ortamı sunarak öğretmen-öğrenci, öğrenci-öğrenci etkileşimi ve iletişimini sağlayarak katılımcılar arasında bir bağ kurulmasına, öğrencilerin kendini özgürce ifade edebilmesini sağlayarak derslere karşı motivasyonlarını ve bağlılıklarını arttırdığı tespit edilmiştir.

\section{Tartışma ve Sonuç}

Öğretmenlerin eğitimde kullanılan teknolojilerin duyuşsal alan hedeflerinin gerçekleşmesindeki etkililiğine yönelik görüşlerine göre duyuşsal alanın alma, tepkide bulunma, değer verme, örgütleme ve kişilik haline getirme süreçlerinde teknolojinin etkililiğine ilişkin görüşlerinin genel anlamda yüksek olduğu görülmektedir. Bu bulgu öğretmenlerin araştırmada incelenen eğitim teknolojilerinin, duyuşsal hedeflerin kazandırılması sürecinde etkili birer araç olduğuna inandıklarını göstermektedir. Araştırmada incelenen eğitim teknolojilerine bakıldığında duyuşsal hedeflerin gerçekleşmesinde en çok akı1lı tahta ön plana çıkarken, sonrasında ise sırasıyla Web 2.0, bilgisayar, tablet PC / ak1llı telefon ve Web 1.0 teknolojilerinin geldiği görülmektedir.

Alanyazın incelendiğinde duyuşsal alan hedefleri üzerinde teknoloji etkililiği ile ilgili araştırmalar sınırlı olmakla birlikte, eğitimde kullanılan teknolojilerin öğrencilerin duyuşsal alan hedeflerini de etkilediği, bu sayede öğrenci başarıları üzerinde olumlu katkılar sağladığı sonucuna ulaşılan çalışmalar bulunmaktadır. Yapılan çalışmalarda akıllı tahtanın motivasyonu ve derse olan ilgiyi arttırdığı için öğrencilerin bilgi ve becerilerini arttırdığı (Yıldızhan, 2013), akıllı tahta uygulamalarının derse yönelik tutum ve motivasyonlarda yükselmeyi sağladığı (Erdem ve Kara, 2016), Web 2.0 araçlarının öğrencinin dersle ilgili motivasyonun, ilginin ve dersin değerine ilişkin anlayışın artmasını sağladığı (Baş, ve Tüzün, 2007; Ramma, Bholoa, Watts ve Nadal, 2017), öğrencinin derse yönelik tutumunu arttırdığı (Katwibun, 2014; Özerbaş, 2012), öğrenmeye ilgisini 
ve tutumunu önemli ölçüde geliştirdiği (Hwang ve Chang, 2016), Web 2.0 uygulamalarının motivasyonun yanı sıra özgüveni de arttırdığı (Kurtuluş, Ada ve Yanık, 2014) ortaya konulmuştur.

Yapılan araştırmalar eğitim ortamında teknolojinin kullanılmasının öğrencilerin ilgisini ve dikkatini çekip ve motivasyonunu arttırarak derse yönelik olumlu tutumlar geliştirmesini, derse önem vermesini ve dersin duyuşsal hedeflerini gerçekleştirmesini sağladığını göstermektedir. Aynı zamanda geleneksel eğitim anlayışı yerine kullanılan teknoloji destekli eğitim uygulamaları öğrencilerin derse olan ilgisini arttırmasına, öğrenme isteği sağlamasına, derse karşı daha duyarlı ve olumlu tutumlar oluşturarak dersle bütünleşmesine yardımcı olmaktadır.

Teknolojinin duyuşsal alan hedeflerin gerçekleştirilmesindeki etkililiğine ilişkin dayanakları akıllı tahta ve Web 2.0 üzerinden incelenmiştir. Öğretmenler, akıllı tahtanın görsel, işitsel ve farklı uygulamalara sahip olmasının öğrencinin derse olan ilgisini arttırdığını, dersi dikkatle takip etmesini sağlayarak derse katılım için öğrenciyi motive ettiğini belirtmişlerdir. $\mathrm{Bu}$ durum öğrencilere kazandırılacak duyuşsal hedeflerin gerçekleşmesi sürecinde akıllı tahtanın öğrencileri motive ettiğini göstermektedir. Benzer şekilde yapılan çalışmalarda da akıllı tahtanın öğrencilerin derse ilgisini ve katılımını arttırdığ görüşünü belirtmişlerdir (Katwibun, 2014; Balkaş ve Barış, 2015; Erduran ve Tataroğlu, 2009; Bush, Priest, ve Coe, 2004; Shenton ve Pagett, 2007; Troff ve Tirotta, 2009; Kaya ve Aydın, 2011). Akıllı tahtanın, öğrencilerin öğrenme ilgisini ve motivasyonunu arttırmak için etkili bir öğrenme aracı olduğunu gösteren çalışmalar bulunmaktadır. Akıllı tahta özel öğrenim ihtiyaçları olan öğrencileri güçlü bir şekilde desteklemektedir (Chou, Chang ve Chen, 2017). Web 2.0 araçlarından EBA'nın kullanımının derse olan ilgiliyi arttırdığı için sınıf yönetimini de kolaylaştırdığı belirtilmiştir (Çakmak ve Taşkıran, 2017).

Web 2.0 araçlarını kullanan öğrencilerin oluşturulan ortamın yapısına uyum sağlayarak öğrencilerin hem birbirleri hem de öğretmenleri ile iletişim oluşturmaları sayesinde, katılımcıların sosyalleşmesinin sağlandığı bir ortam oluştuğu belirtilmiştir. Bu durum Web 2.0 araçları üzerinde birbiriyle bağ kuran, iletişim halinde olan, paylaşımda bulunan katılımcıların içinde bulunduğu ortama uygun bir şekilde hareket ederek sosyal uyum ve özerk davranışlar sağladığını göstermektedir. Benzer şekilde Klimova ve Poulova (2015) sosyal ă̆ üzerinde yer alan ögrencilerin iletişimi arttırdıklarını ve öğrencilerin öğretmen ile kendi aralarında kurdukları ilişki sayesinde sınıf ilişkilerinin gelişmesini sağladığını; Šliogerienè, Masoodi ve Gulbinskienè (2016) Facebook'un özerklik duygusunu geliştirmek için kullanılabileceğini çalışmaları sonucunda bulmuşlardır.

Sonuç olarak akıllı tahta öğrencinin derse ilgi göstermesini, merak ve dikkat etmesini sağlayarak; akıllı tahtada işlem yapma isteği, güveni ve motivasyonu arttırarak dersin duyuşsal hedeflerinin kazandırılmasında olumlu katkı sağlamaktadır. Web 2.0 araçları ise sosyal etkileşim ve ders aracillğ 1 ile öğrencilerin birbiriyle bağ kurduğu, iletişim halinde olduğu, sosyalleştiği, kendini ifade edebildiği, kendine güvendiği ortamları sağlamaktadır. Öğrenme sürecinin sosyal ortamlarındaki bu özellikleri, dersin duyuşsal olarak kazanımlarının gerçekleşmesi sürecinde etkisi olduğunu ortaya koymaktadır. Bu açıdan teknolojinin eğitime entegrasyonunun işlevselleştirilmesi, teknolojiye yönelik mesleki yeterliliklerin incelenmesi, öğretmenlere eğitim hedeflerini kazandırmada teknolojinin kullanımına yönelik kılavuzların oluşturulması önerilmektedir. 


\section{Kaynakça}

Akpınar, E. (2003). Ortaöğretim coğrafya dersleri yazılı sınav sorularının bilişsel düzeyleri. Erzincan Ë̆itim Fakültesi Dergisi, 5(1), 13-21.

Arı, A. (2013). Bilişsel alan sınıflamasında yenilenmiş Bloom, SOLO, Fink, Dettmer taksonomileri ve uluslararası alanda tanınma durumlanı. Uşak Üniversitesi Sosyal Bilimler Dergisi, 6(2), 259- 290. https://doi.org/10.12780/uusbd164

Altınkurt, Y. (2008). Öğrenci devamsızlıklarının nedenleri ve devamsızlığın akademik başarıya olan etkisi. Dumlupınar Üniversitesi Sosyal Bilimler Dergisi, 20, 129-142.

Atılgan, H. (Ed.) (2011). Eğitimde ölçme ve değerlendirme (5. baskı). Ankara: Anı.

Bacanlı, H. (2006). Duyuşsal davranış eğitimi. Ankara: Nobel.

Balkaş, S. R. \& Barış, M. F. (2015). Etkileşimli akıllı tahta kullanımının öğretmen rollerine, sınıf içi etkileşime ve öğrenci motivasyonuna etkisi. Elektronik Eğitim Bilimleri Dergisi, 4(8), 206-222.

Baş, T. \& Tüzün, H. (2007). Aday ögrretmenlerin alan eğitiminde web günlüklerinin (blog'ların) kullanılması. Uluslararası Öğretmen Yetiştirme Politikaları ve Sorunları Konferansı Bildirileri Bakü, Azerbaycan.

Bloom, B. S. (Ed.) (1956). Taxonomy of educational objectives. Handbook I: The cognitive domain. New York: David McKay.

Bush, N., Priest, J., Coe, R. \& Evershed, B. (2004) An exploration of the use of ICT at the Millennium Primary School Greenwich.

http://391u337z5111zjr1i1ntpio4-wpengine.netdna-ssl.com/wp-

content/uploads/2016/04/exploration_ict_greenwich.pdf adresinden 15.05.2018 tarihinde edinilmiştir.

Bümen, N. T. (2006). Program geliştirmede bir dönüm noktasi: Yenilenmiş Bloom taksonomisi. Eğitim ve Bilim, 31(142), 3-14.

Büyüköztürk, Ş., Kılıç-Çakmak, E., Akgün, Ö. E., Karadeniz, Ş. \& Demirel, F. (2012). Bilimsel araştırma yöntemleri (13. Bask1). Ankara: Pegem A Akademi. https://doi.org/10.14527/9789944919289

Chang, C. Y. (2002). Does computer-assisted instruction + problem solving $=$ improved science outcomes? A pioneer study. The Journal of Educational Research, 95(3), 143-150. https://doi.org/10.1080/00220670209596584

Chen, H. R., Chiang, C. H. \& Lin, W.S. (2013). Learning effects of interactive whiteboard pedagogy for students in Taiwan from the perspective of multiple intelligences. Journal of Educational Computing Research, 49(2), 173-187. https://doi.org/10.2190/ec.49.2.c

Chou, P. -N., Chang, C. -C. \& Chen, M. -Y. (2017). Let's draw: Utilizing interactive white board to support kindergarten children's visual art learning practice. Educational Technology \& Society, 20(4), 89-101.

Creswell, J. W. (2017). Araşstırma deseni: Nitel, nicel ve karma yöntem yaklaşımları (3.baskı) (Çev. S. B. Demir). Ankara: Eğiten Kitap.

Çakmak, Z. \& Taşkıran, C. (2017). Sosyal bilgiler öğretmenlerinin perspektifinden eğitim bilişim ağ1 (eba) platformu. Uluslararast Türk Eğitim Bilimleri Dergisi, 5(9), 284-295. https://doi.org/10.17984/adyuebd.02575

Demirel, Ö. (2015). Eğitimde program geliştirme (24. bask1). Ankara: Pegem. 
Dewey, J. (2004). Democracy and education: an introduction to the philosophy of education. India: AAKAR BOOKS.

Durkheim, E. (1956). Education and sociology. New York: The Free Press.

Erdem, E. \& Kara, H. (2016). Kimya dersinde akıllı tahta uygulamalarının öğrenci motivasyonuna ve tutumuna etkisi. Ĕ̈itim ve Öğretim Araştırmalarl Dergisi, 5, 3, s.71-79. https://doi.org/10.17497/tuhed.325108

Erduran, A. ve Tataroğlu, B. (2009). Eğitimde akıllı tahta kullanımına ilişkin fen ve matematik ögretmen görüşlerinin karşılaştırılması. 9th International Educational Technology Conference: IETC Ankara: Hacettepe Üniversitesi. https://doi.org/10.18844/ijire.v4i1.1255

Ersin, P. \& Bayyurt, Y. (2015). Odak grup göüşmeleri. F. N., Seggie ve Y. Bayyurt (Editörler), Nitel araştırma: Yöntem, teknik, analiz ve yaklaşımları (ss.202-218). Ankara: Anı Yayıncilik.

Ertürk, S. (1972). Eğitimde program geliştirme. Ankara: Meteksan.

Gano-Phillips S. (2009). Affective learning in general education. Special Topic: Assessment in University General Education Program, 6(1), 1-43.

Gökyer, N. (2012). Ortaöğretim okullarındaki devamsızlık nedenlerine ilişkin öğrenci görüşleri. Kastamonu Ĕ̈itim Dergisi, 20(3), 913-938.

Hwang, G. J., \& Chang, S. C. (2016). Effects of a peer competition-based mobile learning approach on students' affective domain exhibition in social studies courses. British Journal of Educational Technology, 47(6), pp.1217-1231. https://doi.org/10.1111/bjet.12303

Karasar, N. (2005). Bilimsel araştırma yöntemi (14. Baskı). Ankara: Nobel Yayın Dağıtım.

Katwibun, H. (2014). Using an interactive whiteboard in vocabulary teaching. Proceedings of the Social and Behavioral Sciences, 116, 674-678. https://doi.org/10.1016/j.sbspro.2014.01.278

Kausar, T., Choudhry, B.N. \& Gujjar, A.A. (2008) A comparative study to evaluate the effectiveness of computer assisted instruction (ca1) versus class room lecture (crl) for computer science at ics level. The Turkish Online Journal of Educational Technology, 7(4), 2, ISSN: 1303-6521.

Kaya, H. \& Aydın, F. (2011). Sosyal bilgiler dersindeki coğrafya konularının öğretiminde akıllı tahta uygulamalarına ilişkin öğrenci görüşleri. Zeitschrift Für Die Welt Der Türken Journal Of World $\quad$ Of Turks, ZFWT, 3,1. https://doi.org/10.14527/9786053646051.08

Kaya, F., ve Tümkaya, S. (2017). Sınıf öğretmenliği öğrencilerinin başarı yönelimi, kendini engelleme davranışları ve demografik özelliklerinin okula yabancılaşmayı yordama düzeylerinin incelenmesi. Journal of Human Sciences, 14(1), 747-771. https://doi.org/10.14687/jhs.v14i1.4328

Kıncal, R.Y. (2011). Eğitim bilimine giriş. R.Y. Kıncal (Ed.). Eğitim ve felsefe (s.61-82). Ankara: Grafiker Ofset Yayıncılık.

Klimova, B. \& Poulova, P. (2015). A social networks in education. 12th International Conference on Cognition and Exploratory Learning in Digital Age (CELDA 2015), Ireland: Maynooth

Krathwohl, D.R., Bloom, B. S. \& Masia, B. B. (1973). Taxonomy of educational objectives. Handbook 2: Affective domain. London. Longman Group Limited. 
Kurtuluş, A., Ada, T. \& Yanık, H. B. (2014). Bir ortaokul matematik öğretmeninin Webquestin uygulamasına yönelik görüşü. Eğitimde Nitel Araştırmalar Dergisi, 2(1), 87-106. https://doi.org/10.14689/issn.2148-2624.1.2s4m

Küçükahmet, L. (1999). Öğretimde planlama ve değerlendirme (10. Bask1). İstanbul: Alkım Yayınevi.

Mevarech, Z. R. \& Rich, Y. (1985). Effects of computer-assisted mathematics instruction on disadvantaged pupils' cognitive and affective development. The Journal of Educational Research, 79(1), 5-11. https://doi.org/10.1080/00220671.1985.10885638

Miles, M. B. \& Huberman A.M. (1994). Qualitative data analysis: An expanded sourcebook. (2nd Edition). Calif: Sage Publications.

Miller, M. (2010). Teaching and learning in affective domain. In M. Orey (Ed.), Emerging perspectives on learning, teaching, and technology (p. 93-103). Switzerland: A Global Text

OECD (2016). PISA 2015 Results (Volume I): Excellence and Equity in Education, PISA. Paris: OECD Publishing. https://doi.org/10.1787/9789264266490-en

Özabac1, N. \& Olgun A. (2011). Bilgisayar destekli fen bilgisi öğretiminin fen bilgisi dersine ilişkin tutum, bilişüstü beceriler ve başarısı üzerine bir çalışma. Elektronik Sosyal Bilimler Dergisi, 10(37), 93-107. https://doi.org/10.17719/jisr.20153710636

Özerbaş, M. A. (2012). WebQuest öğrenme ortamının öğrencilerin akademik başarı ve tutumlarına etkisi. Ahi Evran Üniversitesi Kırşsehir Eğitim Fakültesi Dergisi, 13(2), 299-315. https://doi.org/10.17240/aibuefd.2015.15.1-5000128608

Pehlivan, Z. (2006). Resmi genel liselerde ögrenci devamsızlı̆g ve buna dönük okul yönetimi politikaları (Ankara ili örneği). Yayınlanmamış doktora tezi, Ankara Üniversitesi, Eğitim Bilimleri Enstitüsü, Ankara. https://doi.org/10.1501/egifak_0000001110

Ramma, Y., Bholoa, A., Watts, M. \& Nadal, P. S.(2017). Teaching and learning physics using technology: Making a case for the affective domain. Education Inquiry, 9(2), 210-236 https://doi.org/10.1080/20004508.2017.1343606

Senemoğlu, N. (2005). Gelişim öğrenme ve ögretim (12.baskı). Ankara: Gazi Kitabevi.

Shenton, A. \& Pagett, L. (2007). From 'bored' to screen: the use of the interactive whiteboard for literacy in six primary classrooms in England. Literacy, 41(3), 129-136. https://doi.org/10.1111/j.1467-9345.2007.00475.x

Sönmez, V. (2004). Program gelişstirmede ögretmen el kitabı (11.bask1). Ankara: Anı Yayınları.

Šliogerienè, J., Masoodi, M. \& Gulbinskienè, D. (2016). Facebook as a tool in university english language education. Acta Paedagogica Vilnensia, 36, 34-42. https://doi.org/10.15388/actpaed.2016.36.10070

Taş, U. E., Arıcı, Ö., Özarkan, H. B. \& Özgürlük, B. (2016). PISA 2015 ulusal raporu. http://odsgm.meb.gov.tr/test/analizler/docs/PISA/PISA2015_Ulusal_Rapor.pdf adresinden 05.01.2018 tarihinde edinilmiştir.

Troff, B. \& Tirotta, R. (2010). Interactive whiteboards produce small gains in elementary students self-reported motivation in mathematics. Computers \& Education, 54, 379-383. https://doi.org/10.1016/j.compedu.2009.08.019 
Yang, J. Y., \& Teng, Y. W. (2014). Perceptions of elementary school teachers and students using interactive whiteboards in English teaching and learning. Journal of Interactive Learning Research, 25(1), 125-154.

Yenice, N. (2003) Bilgisayar destekli fen bilgisi öğretiminin öğrencilerin fen ve bilgisayar tutumlarına etkisi. The Turkish Online Journal of Educational Technology, 2(4),79-85. https://doi.org/10.17719/jisr.20153710636

Yeşilyurt, E. (2009). İşbirliğine dayalı öğrenmenin öğrenci davranışları üzerindeki etkisine ilişkin öğrenci görüşleri. Fırat Üniversitesi Sosyal Bilimler Dergisi, 19(2), 161-178. https://doi.org/10.18069/fusbed.82121

Yıldırım, A. \& Şimşek, H. (2016). Soysal bilimlerde nitel araştırıma yöntemleri (10.bask1). Ankara: Seçkin Yayıncılık

Yıldızhan, Y. H., (2013). Temel eğitimde akıllı tahtanın matematik başarısına etkisi. Middle Eastern \& African Journal of Education Research, 5, 110-121.

Yin, R. K. (2009). Case study research: Design and methods (4th Ed.). Thousand Oaks, CA: Sage. 